\title{
Scientific reports concerning the impact of interleukin 4, interleukin 10 and transforming growth factor $\beta$ on cancer cells
}

\author{
KONRAD KWAŚNIAK ${ }^{1}$, JUSTYNA CZARNIK-KWAŚNIAK ${ }^{1,2,3}$, ALEKSANDRA MAZIARZ ${ }^{1,2}$, \\ DAVID AEBISHER ${ }^{1,2}$, KINGA ZIELIŃSKA ${ }^{4}$, BOŻENNA KARCZMAREK-BOROWSKA ${ }^{4,5}$, \\ JACEK TABARKIEWICZ ${ }^{1,2}$ \\ ${ }^{1}$ Centre for Innovative Research in Medical and Natural Sciences, Faculty of Medicine, University of Rzeszow, Poland \\ ${ }^{2}$ Department of Immunology, Faculty of Medicine, University of Rzeszow, Poland \\ ${ }^{3}$ Postgraduate School of Molecular Medicine, Medical University of Warsaw, Poland \\ ${ }^{4}$ Department of Clinical Oncology, Clinical Provincial Hospital No. 1 in Rzeszow, Poland \\ ${ }^{5}$ Department of Clinical Fundations of Physiotherapy, Medical Faculty, University of Rzeszow, Poland
}

\begin{abstract}
Cytokines are signalling proteins generated in most part by immune cells that have critical functions in cellular lifespan. Here we present recent data on three selected anti-inflammatory cytokines: interleukin (IL)-10, IL-4 and transforming growth factor $\beta(T G F-\beta)$. IL-10 inhibits the synthesis of major pro-inflammatory cytokines, chemokines, and mediates anti-inflammatory reactions. IL-4 is a multifunctional cytokine which plays a crucial role in the regulation of immune responses and is involved in processes associated with development and differentiation of lymphocytes and regulation of $T$ cell survival. Transforming TGF- $\beta$, which in normal cells or pre-cancerous cells, promotes proliferation arrest which represses tumour growth. In this review, we focus on the influence of IL-10, IL-4 and TGF- $\beta$ on various types of cancer as well as potential of these selected cytokines to serve as new biomarkers which can support effective therapies for cancer patients. This article is presented based on a review of the newest research results.
\end{abstract}

Key words: cancer, anti-inflammatory cytokines, $I L-10, I L-4, T G F-\beta$.

(Centr Eur J Immunol 2019; 44 (2): 190-200)

\section{Introduction}

Cytokines are signalling proteins generated in most part by immune cells that orchestrate immune cell communication and have critical functions in cellular lifespan. For example, they initiate numerous signalling pathways responsible for maturation, differentiation, cell migration, cell survival and serve as activators of several immune cells $[1,2]$. Inflammation is a cytokine-mediated pathophysiological process which rejuvenates injured tissue and removes pathogenic agents that disturb homeostasis. Cytokines can modulate anti-tumour responses as well as promote cell transformation and malignancy during chronic inflammation [2]. Cytokines are small molecular weight proteins which are divided functionally into two groups: pro-inflammatory and anti-inflammatory. Anti-inflammatory cytokines suppress the activity of pro-inflammatory cytokines and consequently downregulate the inflammatory response [3, 4]. Pro- and anti-inflammatory cytokines are also associated with cell rebalance [5]. The potential of immune system-based cancer therapies has driven an intense interest in unravelling the complex cytokine network.

Recent studies discussed in this review were chosen to illustrate current knowledge of interleukin (IL)-10, IL-4 and transforming growth factor $\beta$ (TGF- $\beta$ ) cytokines, and their effect on other cytokines, immune cells (Fig. 1) and tumour cells [6].

\section{Interleukin 10}

IL-10 serves as a mediator of the anti-inflammatory response [7] and as an inhibitor of macrophages and dendritic cells (DCs). Interleukin 10 is the central immune-regulator which affects growth and differentiation of various hematopoietic cells. Additionally, IL-10 functions in immunoglobulin class switching $[8,9]$. Interleukin 10 is produced by monocytes, macrophages and various T cell subsets. DCs, B-cells, NK-cells, eosinophilic granulocytes, myeloid-derived suppressor cells also produce IL-10 [10, 11]. IL-10 is an anti-inflammatory cytokine

Correspondence: Konrad Kwaśniak, Centre for Innovative Research in Medical and Natural Sciences, Faculty of Medicine, University of Rzeszow, 1A, Warzywna St., 35-310 Rzeszów, Poland, e-mail: konkwasniak@gmail.com Submitted: 21.11.2017; Accepted: 12.03.2018 
which inhibits production of the major pro-inflammatory cytokines (IL-1, IL-6, IL-8, IL-12 and TNF- $\alpha$ ) by inhibition of MHC II complex expression, costimulatory of CD80 and CD86. Production of IL-10 by T regulatory lymphocytes (Tregs) is enhanced by IL-2 through the STAT5 signalling axis (STAT molecules participate in intracellular signal transduction after cellular stimulation by cytokines) [12]. The activity of IL-10 is mediated by the IL-10 receptor (IL-10R) [9, 13], which triggers Janus kinases (JAK) consequently activating STAT3 which is both critical for expression of IL-10 and for proliferative and anti-apoptotic functions [14-16]. Activation of STAT3 participates in IL-10-mediated homeostasis of Treg cells, which is essential for its anti-inflammatory function [16]. In addition, production of IL-10 by Tregs has been implicated in a protective mechanism against colon cancer as it suppresses cancer-associated inflammation [17]. Previous studies also suggest a reduced population of IL-10 producing $\mathrm{T}$ regulatory cells in colon cancer $[18,19]$. In contrast, IL-10 is responsible for the emergence of gastric [20, 21], head, neck [22] and breast cancers [23].

Intratumoral $\mathrm{CD}^{+} \mathrm{T}$ cells increase expression of interferon (IFN) $\gamma$ in response to IL-10 [24]. Intratumoral expression of IFN- $\gamma$ induces MHC class I and II expression which is correlated with an improved clinical prognosis $[16,25]$.

IL-10 is an immunosuppressive and anti-inflammatory protein involved in cancer evasion, as previously mentioned [26]. IL-10 also downregulates the immune response to cancer [16] by the induction of neoplastic cell resistance to cytotoxic $\mathrm{T}$ cell (Tc) action. This phenomenon is caused by a low expression or inhibition of MHC I on the cell surface likely resulting in a reduction in expression of the encoding transporters associated with antigen processing TAP-1 and TAP-2 genes [26-28]. Hussain et al. suggest that IL-10 induced by Helicobacter pylori can control production of immunoglobulin (Ig) E [29]. Regulatory mechanisms of IL-10 expression are crucial for developing therapeutic strategies directed against cancer-associated impaired production [7]. In addition to IL-10 expression, variants of the gene encoding IL-10 are also important. Qu et al. showed the impact of three polymorphic sites in the IL-10 gene: -592C >A (rs1800872), -819C >T (rs1800871) and $-1082 \mathrm{~A}>\mathrm{G}$ (rs1800896) on human papilloma virus and Epstein-Barr virus-associated cancers (HEACs). Presence of the $1082 \mathrm{G}$ allele increased the risk for nasopharyngeal cancer in Asians by $74 \%$. These data demonstrate that changes in DNA also have an effect on circulating IL-10 and result in development of HEACs [30].

Salivary IL-10 has been implicated as a biomarker distinguishing healthy individuals from patients with oral squamous cell carcinoma [26]. A correlation between higher levels of salivary IL-10 in poorly-differentiated tumours compared to levels within well-differentiated tumours was found [26], and it was proposed that increases in HLA-G

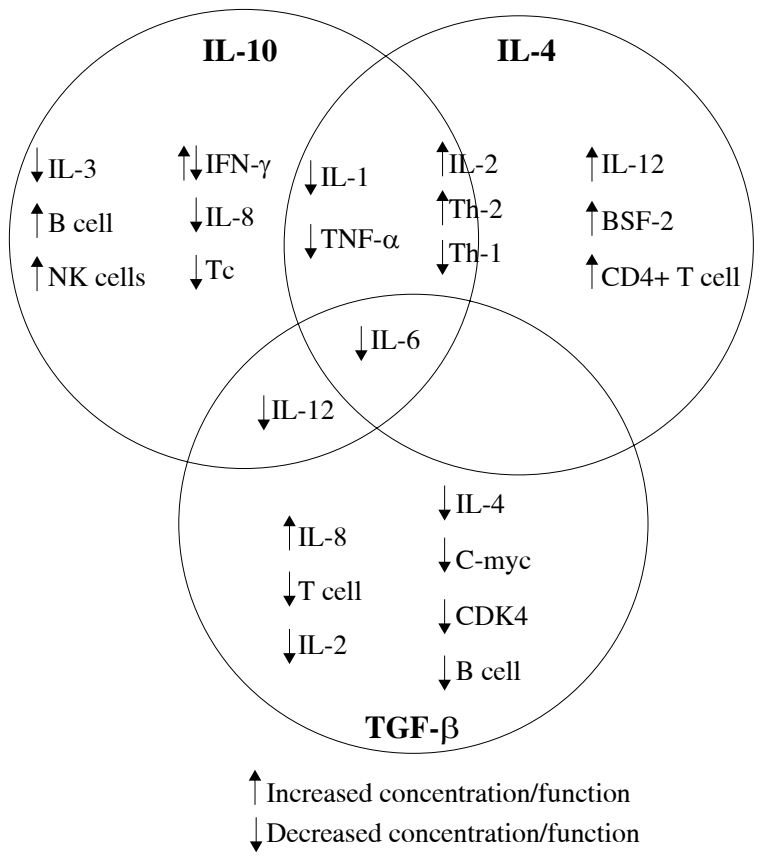

Fig. 1. Effect of IL-10, IL-4 and TGF- $\beta$ on other cytokines and immune cells

and IL-10 expression in tumours aid in immune response evasion [26]. Subsequent studies by Xu et al. on samples from patients with gastric cancer showed that percentages of DC-10 (a unique subset of IL-10 producing myeloid DCs characterized by a high expression of HLA-G) among peripheral blood mononuclear cells (PBMC) were increased in gastric cancer patients compared to healthy controls [31]. The authors found no correlation between HLA-G ${ }^{+}$ DC-10 and levels of plasma soluble HLA-G nor differences between mean fluorescence intensity (MFI) of HLA-G expressed by DC-10 and plasma sHLA-G concentration associated with TNM (tumour/node/metastasis) stages. However, the percentage of HLA-G+ DC-10 was strongly correlated with the tumour grade and peripheral HLA-G ${ }^{+}$ DC-10 may aid immunosuppression in gastric cancer [31].

Induction of calreticulin (CALR) expression (a chaperone protein which enhances DCs maturation and antigen presentation) promoted DC type I maturation by upregulation of costimulatory molecules, MHC II expression, enhancement of IL-12 production and reduction of IL-10 production in vitro [32]. Furthermore, monocyte activity and differentiation to macrophages are regulated by contact with tumour cells or tumour-derived microvesicles (TMVs) [33]. Essa et al. provided evidence confirming the hypothesis that "macrophages recruited to fight against oral squamous cell carcinoma (OSCC) are functionally differentiated within neoplastic stromata" by finding a lower expression of tumour necrosis factor (TNF)- $\alpha$ and IL-12 and a higher expression of IL-10 and M2 macro- 
phages-specific gene expression pattern. This result indicates that M2 macrophages are differentiated from monocytes after recruitment to tumour microenvironments [33]. A study conducted on monocyte-derived macrophages (MDM) which were cultured with or without TMVs from colon cancer cell lines showed that early contact of MDM with TMVs caused a lower secretion of TNF and increased secretion of IL-10 while late contact with TMVs had the opposite effect [34]. Significantly higher serum levels of immunosuppressive cytokines IL- 10 and TGF- $\beta 1$ were found in patients with non-small cell lung cancer in comparison to healthy controls and benign tumours. Moreover, tumour cells increased the expression of the FoxP3 gene by demethylation of the Foxp 3 gene promoter. It was suggested that Foxp3 ${ }^{+} \mathrm{T}$ cells were responsible for secretion of IL-10 and TGF- $\beta$ in tumour-bearing patients [35]. Studies of inflammatory response in association with a risk of colorectal cancer recurrence showed significantly lower plasma concentrations of IL-1, IL-6, IL-10 in patients who had a positive prognosis in comparison to those who experienced postsurgical relapse. In addition, authors found a linear correlation between plasma values of IL-10 and VEGF [36]. Colon cancer cell migration was found to be correlated with levels of IL-10 and TNF- $\alpha$ [37].

In patients with glioblastoma (GMB) with elevated levels of BLyS (B lymphocyte stimulator) in circulation, an immune response of IL- $10^{+}$Breg to vaccination was not observed. The IL-10+Bregs level remained constant before and after administration of vaccine and was not associated with peak anti-vaccine antibody titres, BLyS levels, patient survival rates, progression-free survival or time to radiographic progression of disease. However, there was a significant change in the percentages of B cells in healthy donor PBMC samples upon soluble BLyS addition, but the level of IL- $10^{+}$Bregs remained unchanged. The authors state that "IL10+Bregs may not be a regulatory barrier in the use of BLyS as a humoral adjuvant for vaccine-based cancer immunotherapy" [38]. However, Bregs, which are significantly enhanced in tongue squamous cell carcinoma (TSCC) microenvironments, affects $\mathrm{CD} 4^{+} \mathrm{CD} 25^{-} \mathrm{T}$ cell conversion into Tregs through secretion of IL-10, a predictor of a worse prognosis in patients with this type of cancer [39]. Macrophages exposed to ionizing radiation (IR) were found to sustain cancer cell activity in colon carcinoma [40]. Irradiated macrophages remained viable and metabolically active despite DNA damage. Moreover, irradiated macrophages exhibited a decrease in anti-inflammatory markers IL-10, CD163 and MRC1 genes [40].

IL-10 production has also been found to occur during exposure of skin to ultraviolet (UV) light in studies of skin cancer development in immunosuppressed individuals [7]. Ultraviolet light induced DNA damage can mediate generation of Tregs, Tregs activating macrophages, and keratinocytes to produce IL-10 [41]. After UV radiation, IL-10 can be secreted by activated macrophages that mi- grate into irradiated skin and suppress immune response $[42,43]$. This effect was counteracted by introduction of IL-12 (a pro-inflammatory cytokine) in animal models that were subjected to UV irradiation. Enk et al. suggested that IL-10 can counteract IL-12, inhibiting T helper (Th1) cell activation and simultaneously activating Th2 cells so the overall effect of cytokines in UV exposed skin is biased towards immunosuppression [3, 43].

High IL-10 serum levels were found to be associated with shorter progression-free survival and overall survival rate in patients suffering from multiple myeloma [44]. This suggests that serum IL-10 is a novel and powerful prognostic factor for multiple myeloma [45]. IL-10 has been proposed to be a biomarker for breast cancer although there are no data that show significant associations [41, $46,47]$. Surgical treatment of lung cancer could also increase the number of IL-10 producing cells and negatively influence survival of patients with lung cancer [47].

It was suggested that increased levels of IL-10 could promote cancer development as Cai et al. showed that higher frequencies of IL-10+ tumour-infiltrating B cells were associated with a larger tumour size and disease stage in renal cell carcinoma [48]. Moreover, expression of IL-10 in neoplastic and stromal cells in patients with oral squamous cell carcinoma was also higher than in control groups [49]. Similarly, Nowak et al. found that the level of IL-10 produced by ovarian cancer cells from patients at an advanced stage of disease was higher than produced by ovarian cancer cells at disease inception [50].

We conclude that the impact of IL-10 on tumour cells differs since this cytokine can either enhance or impair an anti-tumour response (Table 1) depending upon cancer type. Results presented in this review have been found to be different for each type of neoplasm.

\section{Interleukin 4}

IL-4 is a pleiotropic cytokine involved in the regulation of immune response associated with growth and survival factors in lymphocytes [51]. The function of IL-4 is regulation of $\mathrm{T}$ cell differentiation via the critical anti-tumour immune response mTOR pathway [52] and as a B cell stimulatory factor $[53,54]$. Cells with CD40L (CD40 ligand) expression after incubation with IL-4 generate a greater amount of B cells subsequently generating anti-tumour $\mathrm{CD}^{+} \mathrm{T}$ cells [55]. IL-4 induces anti-CD40 dependent IgG class switch resulting in synthesis of IgG and IgM antibodies and production of the $\operatorname{IgE}$ antibody from B cells secreted by Th 2 cells [56-58]. IL-4 also promotes Th 2 cell differentiation and inhibits Th1 cells [59].

In cancer microenvironments, IL-4 influences pathways involved in cancer cell survival, proliferation and metastasis [60]. Additionally, IL-4 influences cancer cell migration, invasion and metabolism. All of these processes are mediated via pathways which are activated by the IL-4 receptor 
Table 1. The effects of enhancing and impairing anti-tumour response by IL-10

\begin{tabular}{|c|c|c|}
\hline Cytokine & $\begin{array}{l}\text { The effect of enhancing } \\
\text { anti-tumour response/ } \\
\text { use in cancer therapy }\end{array}$ & The effect of impairing anti-tumour response \\
\hline \multirow[t]{9}{*}{ IL-10 } & \multirow{9}{*}{$\begin{array}{l}\text { IL-10 induces } \\
\text { phosphorylation } \\
\text { of STAT1 leading to } \\
\text { the expression of IFN- } \gamma \\
\text { in intratumoral CD8+ } \\
\text { T cells [24] }\end{array}$} & $\begin{array}{l}\text { IL-10 negatively influences the immune response against cancer by inducing a low expression } \\
\text { or inhibition of MHC I and reducing the expression of } T A P-1, T A P-2 \text { genes [26-28] }\end{array}$ \\
\hline & & Presence of the $1082 \mathrm{G}$ allele causes an increased risk of nasopharyngeal cancer in Asians [30] \\
\hline & & HLA-G and IL-10 aid tumour cells in immune surveillance evasion [26] \\
\hline & & Percentages of DC-10 cells are increased in gastric cancer patients [31] \\
\hline & & Colon cancer cell migration capacity is partly correlated with IL-10 and TNF- $\alpha$ concentration [37] \\
\hline & & Percentage of $\mathrm{HLA}^{-} \mathrm{G}^{+} \mathrm{DC}-10$ is strongly associated with the tumour grade [31] \\
\hline & & $\begin{array}{l}\text { Significantly higher levels of serum IL-10 and TGF- } \beta 1 \text { were found in individuals with non-small } \\
\text { cell lung cancer [35] }\end{array}$ \\
\hline & & $\begin{array}{l}\text { Conversion of } \mathrm{CD} 4{ }^{+} \mathrm{CD} 25^{-} \mathrm{T} \text { cells into Tregs by } \mathrm{IL}-10 \text { predicts a worse prognosis in patients } \\
\text { with cancer } \\
\text { Breg } \mathrm{CD} 19^{+} \text {in TSCC is significantly higher than in adjacent normal tissue [39] }\end{array}$ \\
\hline & & $\begin{array}{l}\text { Higher frequencies of IL-10+ cells among tumour-infiltrating B cells correlate with a larger tumour } \\
\text { size and higher disease stage } \\
\text { IL- } 10^{+} \text {B cells promote cancer development and/or inhibit anti-tumour immunity in vivo [48] }\end{array}$ \\
\hline
\end{tabular}

Table 2. Enhancing effects of IL-4 in anti-tumour response

\begin{tabular}{cll}
\hline Cytokine & The effect of enhancing anti-tumour response/use in cancer therapy & $\begin{array}{l}\text { The effect of impairing } \\
\text { anti-tumor response }\end{array}$ \\
\hline IL-4 & $\begin{array}{l}\text { Patients with Barrett's oesophagus have a higher proportion of IL-4 producing CD4+ T cells } \\
\text { compared to healthy individuals [68] }\end{array}$ & $\begin{array}{l}\text { Not reported in cited } \\
\text { publications }\end{array}$ \\
\cline { 2 - 2 } $\begin{array}{l}\alpha-\text {-GalCer, MPL and E7 DNA vaccine can be a rational combination of adjuvants providing } \\
\text { opportunities for the development of therapeutic vaccines for cervical cancer [78] }\end{array}$ & $\begin{array}{l}\text { Synergizing tumour-Gal and CpG1826 can be a tumour-specific immunotherapy against human } \\
\text { cancer by reduction of IL-4 and IL-5 expression [79] }\end{array}$ \\
$\begin{array}{l}\text { Selective blocking of Kv1.1 in CD4+ T resulted in exclusive secretion of TNF- } \alpha \text { by T cells } \\
\text { without elevating IFN- } \gamma, \text { IL-10 and IL-4 in patients with cancer or chronic infectious diseases [80] }\end{array}$ \\
$\begin{array}{l}\text { Increased concentration of MCP-3 or sIL-4R tertile in serum may indicate which men are more } \\
\text { vulnerable to colorectal polyps [84] }\end{array}$ \\
\hline
\end{tabular}

(IL-4R) through JAKs protein phosphorylation. Predominant pathways are IRS/PI3K/AKT and JAK/STAT6 and mTOR [52]. IL-4 receptors are activated and expressed in various types of cancers: pancreatic [61], bladder [42], malignant glioma [62], ovarian [63], lung [64], breast [65] and colon [66] cancer. Cancer cells also produce IL-4 [67] and this cytokine functions as an activator of tumour-associated macrophages and myeloid-derived suppressor cells which mediate pro-tumour activity [56]. These data implicate that IL-4 is an important regulator in tumour microenvironments and enhances anti-tumour response effects (Table 2).

Recent data suggest that higher frequencies of IL-4 production are involved in switching from Th1 response in oesophagitis to a Th2 response in Barrett's oesophagus and in metaplastic transformation. A higher proportion of $\mathrm{CD}^{+}$ T cells compared to healthy and tumour cells in Barrett's tissue indicating a Th2 profile [68] and IL-4 induced Th2 cell proliferation [69] have recently been reported. Sahoo et al. suggested that Th2 and Tfh ( $\mathrm{T}$ follicular helper) cells utilize specific mechanisms for regulation of IL-4 expression. In contrast to Th2, regulation mechanisms of Tfh-derived IL-4 are not fully elucidated. Understanding molecular mechanisms for IL-4 expression and function in both cell subsets as the authors suggest, will be beneficial for the development of future therapeutic interventions [70].

IL-4 can also regulate proliferation, differentiation, and apoptosis of various cell types [71-74]. IL-4 is also implicated in disease stabilization and modification of the tumour growth rate, inducing tumour shrinkage and cell death without severe side effects. This suggests a possible adjuvant role for IL-4 in the treatment of malignant diseases [4], although, Li et al. states that "IL-4 is clearly a double-edged sword for the tumour" since IL-4 has both potential in tumour therapy and in tumour development [75]. 
Nishio et al. suggest that IL-4 promotes morphological changes of peripheral blood monocyte-derived macrophages. Results showed that additional IL-4 exposure significantly influenced morphology of TE-8, TE-11 and TE-15 cell lines [69]. IL-4 is involved in differentiation of monocytes into dendritic cells via activation of the JAK3STAT6 pathway, required for acquisition of the dendriticcell-specific demethylation and expression signature, following STAT6 binding. However, the IL-4R signalling pathway can be omitted during STAT6 activation following DC-specific methylation changes in the absence of IL-4 [76]. Studies performed by Colangelo et al. showed that miR-27a is a negative regulator of apoptotic and autophagy pathways in human colorectal cancer cells and suggest that miR-27a impairs the cell response to drug-induced immune cell-death (ICD) through the regulatory axis with CALR. Moreover, a high expression of miR-27a impeded dendritic cell maturation, increased secretion of IL-4, IL- 6 and IL-8 and negatively influenced CD4 $4^{+}$T-cell IFN- $\gamma$ production and proliferation [77]. In a subsequent study, the combined adjuvant activity of $\alpha$-Galactosylceramide ( $\alpha$-GalCer) and Monophosphoryl lipid A (MPL) in DNA vaccine-induced protective and antitumor immunity in a cervical cancer model was investigated. The results showed that DNA vaccine adjuvanted with a combination of $\alpha$-GalCer and MPL caused a significant increase in lymphocyte proliferation, cytotoxic T cell activity, IFN- $\gamma$, IL-4 and IL-12 responses, and response against tumour cells. The combination of $\alpha$-GalCer and MPL results in more effective immunostimulation compared to the DNA vaccine combined with individual adjuvants or unadjuvanted DNA vaccine. Therefore, application of rational combinations of adjuvants provides opportunities for the development of therapeutic vaccines for cervical cancer [78]. Dong et al. suggest that vaccination by synergizing tumour-Gal and CpG1826 (cytosine-phosphorothioate-guanine, the TLR9 (CD289) agonist) caused redirection of Th2 responses toward Th1 with enhanced IL- 2 and IFN- $\gamma$ and reduced IL-4 and IL-5 expression. Thus, a novel synergized vaccine against murine colon cancer can be further developed as a tumour-specific immunotherapy against human cancer [79]. A study of human T cells incubated with the Kv1.1-selective blocker Dendrotoxin-K (DTX-K) showed that DTX-K induced an exclusive secretion of TNF- $\alpha$ by normal human T cells without elevating IFN- $\gamma$, IL-10 and IL-4 secretion unlike 'classical' TCR activation (via the TCR/CD3 complex) that generates a much higher secretion of TNF- $\alpha$, IFN- $\gamma$, IL-10 and IL- 4 . The authors hypothesize that selective blocking of $\mathrm{Kv} 1.1$ in $\mathrm{CD}^{+}{ }^{+} \mathrm{T}$ cells in patients with cancer or chronic infectious diseases is therapeutic due to beneficial secretion and delivery of TNF- $\alpha$ to disease-affected sites, induction of recruitment and extravasation of curative immune cells and factors, and improvement of drug accessibility to the brain and peripheral organs, and TNF- $\alpha$-induced increases in permeability of organ barriers [80].

A study performed on patients suffering from salivary gland tumours to assess Th1 and Th2 cytokine levels did not indicate any significant differences in the serum level of IFN- $\gamma$ and IL- 4 between tumour-bearing patients compared to healthy control subjects or between those bearing benign and malignant salivary gland tumours. This result suggests that IL-4 and IFN- $\gamma$ are not associated with salivary gland tumours [81]. Lam et al. studied the association between serum cytokines (IL-6, IL-8, TNF- $\alpha$, IFN- $\gamma$, IL-1 $\beta$, IL-2, IL-4, IL-10, IL-12 and IL-13) and oral human papillomavirus (HPV) clearance in patients with prevalent HPV, incident HPV and no HPV. Cytokines such as IL-4, IL-1 $\beta$, IL-12 and IL-13 displayed low detectability and the detection of these cytokines was not associated with reduced oral HPV clearance. Nevertheless, high serum levels of TNF- $\alpha$ were associated with reduced clearance of oral HPV infection in both men and women, while a high IL-2 concentration was associated with reduced clearance only in men [82].

Lee et al. suggest that JMJD6 (Jumonji domain-containing protein 6) induces transcription of IL-4 by binding to its promoter region indicating that the JMJD6-IL4 axis is important in oral cancer stem cells. Jumonji domain-containing protein 6 is a molecular determinant of the cancer stem cell phenotype and its inhibition may be an effective therapeutic modality against oral cancer [83]. Comstock et al. found an association between monocyte chemotactic protein-3 (MCP-3) and soluble IL-4 receptor (sIL-4R) with occurrence of colorectal polyps. These findings indicate that serum factors such as sIL-4R can be potentially useful for prediction of the occurrence of colorectal polyps [84].

Freshly isolated lymphoma cells activated by multimeric CD40L and IL-4 in order to support their survival in vitro varied in sensitivity to lenalidomide, and the regulatory effect of Tregs on lymphoma cells ranged from suppression to a benefit in individual patients. Lenalidomide potentiated or attenuated Treg effects on the survival of freshly isolated lymphoma cells [85].

\section{Transforming growth factor- $\beta$}

TGF- $\beta$ is a cytokine involved in several functions in a variety of cell types, including regulation of proliferation, differentiation, wound healing, development, cytokine secretion and motility in cancer cells. These processes have critical functions in tumour progression [86-88]. TGF- $\beta$ binds with high affinity to the transmembrane TGF- $\beta$ type II receptor via receptor TGF- $\beta$ type I to activate T $\beta R 1$ kinase [89]. Activated T $\beta R 1$ phosphorylates associated SMAD family member receptors (Receptor regulated Smads - R Smads) Smad2 and Smad3. Phosphorylated Smad2/Smad3 creates a complex with Smad4 termed the Smad factor and translocates into the nucleus. Inactivation of Smad4 results in impairment of the TGF- $\beta$ 
Table 3. The influence of TGF- $\beta$ on tumour microenvironment

\begin{tabular}{|c|c|c|}
\hline Cytokine & The effect of enhancing anti-tumour response/use in cancer therapy & The effect of impairing anti-tumour response \\
\hline \multirow[t]{6}{*}{ TGF- $\beta$} & $\begin{array}{l}\text { TGF- } \beta \text { leading to tumour suppression functions through an EMT and } \\
\text { mediated disruption of a lineage-specific transcriptional network [96] }\end{array}$ & $\begin{array}{l}\text { Up-regulation of CXCR } 2 \text { and TGF- } \beta \text { leads to } \\
\text { changes in ovarian cancer towards a more invasive } \\
\text { phenotype [111] }\end{array}$ \\
\hline & $\begin{array}{l}\text { Zyxin activation can play a critical role in regulation of Yap protein } \\
\text { TGF- } \beta \text { and the Hippo pathway may be good therapeutic targets against } \\
\text { cancer [97] }\end{array}$ & $\begin{array}{l}\text { The } P R R X 2 \text { gene may be involved in a mechanism } \\
\text { contributing induction of TGF- } \beta \text { and in } \\
\text { consequence invasion of epithelial mesenchymal } \\
\text { transition in breast cancer [43] }\end{array}$ \\
\hline & $\begin{array}{l}\text { Salinomycin as an inhibitor of TGF- } \beta 1 \text {-induced EMT may be a new } \\
\text { class of anti-cancer drugs [105] }\end{array}$ & $\begin{array}{l}\text { The E2F5/p38/pSMAD3L axis plays an important } \\
\text { role in converting tumour-suppressive TGF- } \beta \\
\text { signalling into pro-tumorigenic signalling in } \\
\text { prostate cancer cells } \\
\text { Reduction of E2F5 and p38 genes leads to the arrest } \\
\text { of prostate cancer cells in the G1 phase of the cell } \\
\text { cycle [115] }\end{array}$ \\
\hline & $\begin{array}{l}\text { Breaking of the TGF- } \beta / \text { Crk axis may be an effective target of cancer } \\
\text { therapy } \\
\text { TGF- } \beta \text { increases CrkI which plays a central role for EMT [100] }\end{array}$ & $\begin{array}{l}\mathrm{B} 2 \mathrm{M} \text { which is regulated via the TGF- } \beta \text { signalling } \\
\text { pathway is a positive regulator in the proliferation, } \\
\text { migration and invasion of ovarian cancer cells [116] }\end{array}$ \\
\hline & $\begin{array}{l}\text { Cdh1 could be a therapeutic target for endometrial cancer and other } \\
\text { human cancers and shows inverse relationship between: Cks1/Skp2 } \\
\text { and p } 27 \text { and/or dysregulated TGF- } \beta \text { signalling [101] }\end{array}$ & $\begin{array}{l}\text { TRIM } 25 \text { promotes cell migration and invasion by } \\
\text { activating the TGF- } \beta \text { pathway [117] }\end{array}$ \\
\hline & $\begin{array}{l}\text { TGF- } \beta \text { RII and FZD-7 inhibit proliferation and metastasis of human } \\
\text { hepatocellular carcinoma (HCC) cells [102] }\end{array}$ & $\begin{array}{l}\text { TGF- } \beta \text { rather than activin is crucial for mediating } \\
\text { IR-induced effects on cell motility [118] }\end{array}$ \\
\hline
\end{tabular}

PX-866 and raloxifene downregulate the PI3K/Akt pathway and upregulate TGF- $\beta$ and in consequence decrease proliferation of breast cancer cells [104]

Androgen may inhibit expression of TGF- $\beta$ in mesenchymal stem cells and blockade treatment in prostate cancer therapy [106]

Silencing of the USP4 gene can inhibit invasion of cancer via the Relaxin/TGF- $\beta 1 /$ Smad2/MMP-9 signal

The USP4 gene is an attractive target for breast cancer therapy [107]

Curcumin may inhibit invasion and metastasis of papillary thyroid cancer by suppressing the TGF- $\beta / \mathrm{Smad} 2 / 3$ pathway and down-regulating expression of $M M P-2$ and $M M P-9$ genes [108]

Nobiletin has an influence on TGF- $\beta 1 / \mathrm{Smad} 3$ signalling and prevents epithelial-mesenchymal transition [109]

The TGF- $\beta$-PMEPA1 axis could be a new therapeutic target for breast cancer [110]

SDPR expression is downregulated in breast cancer tissues and supresses breast cancer by blocking TGF- $\beta$-induced EMT [113]

The Slug/Wnt-5b/MMP-10 signalling axis is stimulated by TGF- $\beta$ in human oral squamous cell carcinoma and supresses expression of SDPR which could reduce cell proliferation, invasion and promote cell apoptosis [114]

signalling pathway which is often found in pancreatic cancer [86]. With regards to cancer, TGF- $\beta$ has contrary functions as a tumour suppressor in invasion metastasis and as a promoter in later stages (Table 3 ) [86, 87, 89]. In lung cancer cells, it was demonstrated that epigenetically silenced TGF- $\beta$ co-receptor endoglin takes advantage of the pro-invasive and pro-metastatic effects of TGF- $\beta$. In the case of melanoma formation, TGF- $\beta$ signalling leads to secretion of IL-8, leading to the formation of capillaries and angiogenesis. TGF- $\beta$ signalling also supports tumour phenotypes and associated fibroblasts, promotes epithelial-mesenchymal transition (EMT), increases local invasion and cancer [87]. In early cancer stages, the role of TGF- $\beta$ has been well documented $[87,90]$, however, TGF- $\beta$ may also promote tumour progression in more advanced stages [91]. TGF- $\beta$ mediates the inhibition of T cell proliferation, 
reduces IL-2 production, downregulates c-myc, upregulates cyclin-dependent kinase inhibitors, and mediates the inhibition of $\mathrm{T}$ cell proliferation. $\mathrm{T}$ cells proliferation can be restored by costimulation with CD28 which is important in blocking TGF- $\beta[92,93]$.

In summary, TGF- $\beta$ is expressed in most cell types and when it is bioactive, it can bind to various non-receptor cell surface proteins such as decorin and betaglycan which also regulate its bioavailability [94]. Additionally, this protein in normal cells or pre-cancerous cells promotes proliferation arrest and consequently represses tumour growth while in advanced tumour cells promotes EMT and tumour metastasis. These contrary functions can arise from the complex regulation network among various types of parallel TGF- $\beta$ pathways $[94,95]$.

David et al. studied dual effects of TGF- $\beta$ in pancreatic ductal adenocarcinoma. The authors showed that TGF- $\beta$ can act pro-tumorigenic by induction of an epithelial-mesenchymal transition (EMT). On the other hand, it also caused lethal EMT by converting TGF- $\beta$-induced transcriptional factor Sox 4 from pro-tumorigenic into pro-apoptotic [96]. Hypoxia-induced TGF- $\beta$ may also participate in regulation of Hippo signalling (a pathway which affects the control of organ size, cell growth and tissue homeostasis) through Zyxin. Moreover, TGF- $\beta$ also affects functioning of tumour suppressors (Lats2) and oncogenes (Yap). Thus, it has been suggested that investigations concerning mutual regulation of hypoxia by TGF- $\beta$ and the Hippo pathway may afford therapeutic strategies against cancer [97]. Moreover, it was demonstrated that hypoxia promoted the secretion of exosomes in cancer cells which contain the immunosuppressive cytokines TGF- $\beta$ and IL-10 [98]. Farhana et al. showed that micro RNA miR-1207 is involved in regulating stemness in colonic epithelial cells in African-Americans. Additionally, miR-1207 induced a higher expression of TGF- $\beta$ in normal human colonic epithelial cells [99]. New signalling cooperation between TGF- $\beta$ and Crk (signalling adaptor protein) forms was found by Elmansuri et al. and they suggest that the TGF- $\beta /$ Crk axis may become an effective target for cancer therapy [100]. Cadherin-1 (Cdh1) was found to be the master regulator of TGF- $\beta$-induced preservation of $\mathrm{p} 27$ tumour suppressor activity. Consequently, Cdh1 appears to be a potential therapeutic target for endometrial cancer and other human cancers showing an inverse relationship between Cks1/Skp2 and p27 and/or dysregulated TGF- $\beta$ signalling [101]. Chen et al. demonstrated that simultaneous blocking of TGF- $\beta$ and the $\mathrm{Wnt} / \beta$-catenin pathway by short hairpin RNA (shRNA) silencing TGF- $\beta$ receptor II (RII) and Frizzled receptor (FZD)-7, exerted a synergistic anti-tumour effect on human hepatocellular carcinoma (HCC) cells. These data suggest the development of a novel treatment strategy which may have better efficiency in treatment of HCC [102]. It was also shown that PX-866 (an inhibitor of phosphoinositide-3-kinase) [103] and raloxifene (a competitive ligand of oestrogen receptor) downregulate the PI3K/Akt pathway and upregulate TGF- $\beta$ caused by a decrease in transcription of hTERT (human telomerase reverse transcriptase) and Cyclin D1 and other genes which consequently decrease proliferation of breast cancer cells [104]. Moreover, salinomycin (a potassium ionophore antibiotic) can be used in breast cancer therapy as an inhibitor of TGF- $\beta 1$-induced EMT and may be a promising tool of anti-cancer treatment [105]. In another study, the authors agreed with previous studies indicating that androgen might inhibit expression of TGF- $\beta$ in mesenchymal stem cells (MSCs) and can block treatment in clinical prostate cancer therapy. Androgen blockade may elicit the expression of TGF- $\beta$ in mesenchymal stem cells leading to transformational androgen-dependent human prostate cancer cells in an androgen-independent manner [106].

Studies conducted on breast cancer cells show that silencing the USP4 gene can inhibit invasion of this cancer via a Relaxin/TGF- $\beta 1 /$ Smad2/MMP-9 signal making this gene an attractive target for breast cancer therapy [107]. Moreover, curcumin may inhibit invasion and metastasis of papillary thyroid cancer by suppressing the TGF- $\beta /$ Smad $2 / 3$ pathway and subsequently downregulating expression of MMP-2 and MMP-9 matrix metalloproteinases [108]. Nobiletin, a polymethoxy flavonoid from Citrus depressa, also has an influence on TGF- $\beta 1 /$ Smad3 signalling and prevents EMT [109]. Additionally, the TGF- $\beta$-PMEPA1 axis (PMEPA1 - prostate transmembrane protein, androgen-induced 1) could serve as a new therapeutic target for breast cancer treatment [110]. Interestingly, volatile anaesthetics increased the expression of TGF- $\beta$ and other genes, while upregulation of TGF- $\beta$ enhanced ovarian cancer aggressiveness [111]. It has been suggested that TGF- $\beta$ can induce bladder cancer via mTORC2 signalling [112] whereas upregulation of PRRX2 (paired related homeobox 2) gene may be a mechanism contributing to TGF- $\beta$-induced invasion and EMT in breast cancer [43]. Tian et al. showed that the expression of serum deprivation response factor (SDPR) was decreased in breast cancer tissue and SDPR supressed progression of breast cancer by blocking TGF$\beta$-induced EMT [113]. Moreover, TGF- $\beta$ is involved in invasion of oral squamous cell carcinoma through the upregulation of matrix metalloproteinase (MMP)-10 expression [114]. The E2F5/p38/pSMAD3L axis is involved in converting tumour-suppressive TGF- $\beta$ signalling into pro-tumorigenic signalling in prostate cancer cells [115]. A study of epithelial-type ovarian tumours showed that beta-2-microglobulin (B2M) is involved in regulation of proliferation, migration and invasion of ovarian cancer cells regulated via the TGF- $\beta$ signalling pathway [116]. In addition, a study on gastric cancer showed that Tripartite Motif Containing 25 (TRIM25) might promote cell migration and invasion by activating the TGF- $\beta$ pathway [117].

Rao et al. tested ionizing radiation (IR), a major cancer treatment modality, on lung and pancreatic carcinoma cells 
in view of the possibility that IR leads to secondary malignancies. The authors observed that IR induced the synthesis and secretion of both TGF- $\beta 1$ and activin A as well as hyperactivation of intracellular TGF- $\beta$ /activin signalling. Generally, the results obtained indicated that irradiation contributes to EMT-associated changes like metastasis, cancer stem cell formation and chemoresistance of tumour cells via activation of TGF- $\beta$ signalling [118].

In conclusion, a better understanding of the TGF- $\beta$ pathway will improve our ability to target it, providing more tools for cancer prevention [44]. Studies have demonstrated that microRNAs also take part in controlling pathways that play a critical role in cellular processes [119, 120]. For example, miR-187 was shown to suppress the progression of colorectal cancer by controlling TGF- $\beta$ / Smad-mediated EMT [121]. It has been suggested that siRNA may provide a potential therapeutic application for patients with various tumour types [121].

\section{Conclusions}

The data described herein show variation in the influence of IL-10, IL-4 and TGF- $\beta$ cytokines and the differences depend on the type of cancer. These results are likely due to the complexity of pathways and axes in which other molecules participate; this results in changes in protein conformation, methylation profile and regulation of the expression level. Moreover, besides having anti-cancer properties, cytokines facilitate cancer cell evasion from immunosurveillance mechanisms, thereby promoting survival of cancer cells. Elucidation of IL-10, IL-4 and TGF- $\beta$ function, pathways in which they participate, and processes in which they are regulated by other molecules such as non-coding RNAs such as miR-27a, miR-187, and miR-1207 is needed for the realization of new effective therapies for cancer patients.

\section{Acknowledgements}

The article was performed within the project of the Center for Innovative Research in Medical and Natural Sciences realized by the University of Rzeszow, cofinanced within the Regional Operational Program for the Podkarpackie Province for the years 2007-2013, contract number UDA-RPPK.01.03.00-18-004/12-00.

The authors declare no conflict of interest.

\section{References}

1. Su D-L, Lu Z-M, Shen M-N, et al. (2012): Roles of Pro- and Anti-Inflammatory Cytokines in the Pathogenesis of SLE. BioMed Res Int 2012: e347141.

2. Landskron G, De la Fuente M, Thuwajit P, et al. (2014): Chronic Inflammation and Cytokines in the Tumor Microenvironment. J Immunol Res 2014: e149185.
3. Opal SM, DePalo VA (2000): ANti-inflammatory cytokines. Chest 117: 1162-1172.

4. Sultani M, Stringer AM, Bowen JM, Gibson RJ (2012): AntiInflammatory Cytokines: Important Immunoregulatory Factors Contributing to Chemotherapy-Induced Gastrointestinal Mucositis. Chemother Res Pract 2012: e490804.

5. Jurjus A, Eid A, Al Kattar S, et al. (2015): Inflammatory bowel disease, colorectal cancer and type 2 diabetes mellitus: The links. BBA Clin 5: 16-24.

6. Dranoff G (2004): Cytokines in cancer pathogenesis and cancer therapy. Nat Rev Cancer 4: 11-22.

7. Iyer SS, Cheng G (2012): Role of Interleukin 10 Transcriptional Regulation in Inflammation and Autoimmune Disease. Crit Rev Immunol 32: 23-63.

8. Kühn R, Löhler J, Rennick D, et al. (1993): Interleukin-10deficient mice develop chronic enterocolitis. Cell 75: 263 274.

9. Trifunović J, Miller L, Debeljak Ž, Horvat V (2015): Pathologic patterns of interleukin 10 expression - A review. Biochem Medica 25: 36-48.

10. Sabat R (2010): IL-10 family of cytokines. Cytokine Growth Factor Rev 21: 315-324.

11. Moore GE, Shuldiner AR, Zmuda JM, et al. (2001) Obesity gene variant and elite endurance performance. Metabolism 50: 1391-1392.

12. Tsuji-Takayama K, Suzuki M, Yamamoto M, et al. (2008): The Production of IL-10 by Human Regulatory T Cells Is Enhanced by IL-2 through a STAT5-Responsive Intronic Enhancer in the IL-10 Locus. J Immunol 181: 3897-3905.

13. Opal SM, Wherry JC, Grint P (1998): Interleukin-10: Potential Benefits and Possible Risks in Clinical Infectious Diseases. Clin Infect Dis 27: 1497-1507.

14. Murray PJ (2005): The primary mechanism of the IL-10-regulated antiinflammatory response is to selectively inhibit transcription. Proc Natl Acad Sci U S A 102: 8686-8691.

15. Murray PJ (2006): Understanding and exploiting the endogenous interleukin-10/STAT3-mediated anti-inflammatory response. Curr Opin Pharmacol 6: 379-386.

16. Oft M (2014): IL-10: Master Switch from Tumor-Promoting Inflammation to Antitumor Immunity. Cancer Immunol Res 2: 194-199.

17. Dennis KL, Blatner NR, Gounari F, Khazaie K (2013): Current status of IL-10 and regulatory T-cells in cancer. Curr Opin Oncol 25: 637-645.

18. Blatner NR, Mulcahy MF, Dennis KL, et al. (2012): Expression of ROR $\gamma \mathrm{t}$ marks a pathogenic regulatory $\mathrm{T}$ cell subset in human colon cancer. Sci Transl Med 4: 164ra159.

19. Correale P, Rotundo MS, Del Vecchio, et al. (2010): Regulatory (FoxP3+) T-cell tumor infiltration is a favorable prognostic factor in advanced colon cancer patients undergoing chemo or chemoimmunotherapy. J Immunother Hagerstown Md 33: 435-441.

20. Kuo W-H, Huang C-Y, Fu C-K, et al. (2014): Effects of interleukin-10 polymorphisms and smoking on the risk of gastric cancer in Taiwan. Vivo Athens Greece 28: 967-971.

21. Haas M, Dimmler A, Hohenberger W, et al. (2009): Stromal regulatory T-cells are associated with a favourable prognosis in gastric cancer of the cardia. BMC Gastroenterol 9: 65 .

22. Alhamarneh O, Agada F, Madden L, et al. (2011): Serum IL10 and circulating CD4(+) CD25(high) regulatory T cell numbers as predictors of clinical outcome and survival in patients with head and neck squamous cell carcinoma. Head Neck 33: 415-423. 
23. Ménétrier-Caux C, Gobert M, Caux C (2009): Differences in Tumor Regulatory T-Cell Localization and Activation Status Impact Patient Outcome. Cancer Res 69: 7895-7898.

24. Emmerich J, Mumm JB, Chan IH, et al. (2012): IL-10 Directly Activates and Expands Tumor-Resident CD8+ T Cells without De Novo Infiltration from Secondary Lymphoid Organs. Cancer Res 72: 3570-3581.

25. Walsh MD, Dent OF, Young JP, et al. (2009): HLA-DR expression is associated with better prognosis in sporadic Australian clinicopathological Stage C colorectal cancers. Int J Cancer 125: 1231-1237.

26. Gonçalves AS, Arantes DAC, Bernardes VF, et al. (2015): Immunosuppressive mediators of oral squamous cell carcinoma in tumour samples and saliva. Hum Immunol 76: 52-58.

27. Petersson M, Charo J, Salazar-Onfray F, et al. (1998): Constitutive IL-10 Production Accounts for the High NK Sensitivity, Low MHC Class I Expression, and Poor Transporter Associated with Antigen Processing (TAP)-1/2 Function in the Prototype NK Target YAC-1. J Immunol 161: 2099-2105.

28. Kurte M, López M, Aguirre A, et al. (2004): A Synthetic Peptide Homologous to Functional Domain of Human IL-10 Down-Regulates Expression of MHC Class I and Transporter Associated with Antigen Processing 1/2 in Human Melanoma Cells. J Immunol 173: 1731-1737.

29. Hussain K, Letley DP, Greenaway AB, et al. (2016): Helicobacter pylori-Mediated Protection from Allergy Is Associated with IL-10-Secreting Peripheral Blood Regulatory T Cells. Front Immunol 7: 71.

30. Qu K, Pang Q, Lin T, et al. (2016): Circulating interleukin-10 levels and human papilloma virus and Epstein-Barr virusassociated cancers: evidence from a Mendelian randomization meta-analysis based on 11,170 subjects. OncoTargets Ther 9: 1251-1267.

31. Xu D-P, Shi W-W, Zhang T-T, et al. (2016): Elevation of HLA-G-expressing DC-10 cells in patients with gastric cancer. Hum Immunol 77: 800-804.

32. Liu X, Li J, Liu Y, et al. (2016): Calreticulin acts as an adjuvant to promote dendritic cell maturation and enhances antigen-specific cytotoxic $\mathrm{T}$ lymphocyte responses against non-small cell lung cancer cells. Cell Immunol 300: 46-53.

33. Essa AAM, Yamazaki M, Maruyama S, et al. (2016): Tumour-associated macrophages are recruited and differentiated in the neoplastic stroma of oral squamous cell carcinoma. Pathology (Phila) 48: 219-227.

34. Baj-Krzyworzeka M, Mytar B, Szatanek R, et al. (2016): Colorectal cancer-derived microvesicles modulate differentiation of human monocytes to macrophages. J Transl Med 14: 36.

35. Ke X, Zhang S, Xu J, et al. (2016): Non-small-cell lung cancer-induced immunosuppression by increased human regulatory T cells via Foxp3 promoter demethylation. Cancer Immunol Immunother 65: 587-599.

36. Caro GD, Carvello M, Pesce S, et al. (2016): Circulating Inflammatory Mediators as Potential Prognostic Markers of Human Colorectal Cancer. PLoS One 11: e0148186.

37. Berkovich L, Ghinea R, Majdop S, et al. (2016): Postcolectomy Peritoneal Environment Increases Colon Cancer Cell Migration Capacity. Gastroenterol Res Pract 2016: 2540397.

38. Saraswathula A, Reap EA, Choi BD, et al. (2016): Serum elevation of B lymphocyte stimulator does not increase regulatory B cells in glioblastoma patients undergoing immunotherapy. Cancer Immunol Immunother 65: 205-211.

39. Zhou X, Su Y-X, Lao X-M, et al. (2016): CD19+IL-10+ regulatory B cells affect survival of tongue squamous cell carcino- ma patients and induce resting CD4+ T cells to CD4+Foxp3+ regulatory T cells. Oral Oncol 53: 27-35.

40. Pinto AT, Pinto ML, Cardoso AP, et al. Ionizing radiation modulates human macrophages towards a pro-inflammatory phenotype preserving their pro-invasive and pro-angiogenic capacities. Sci Rep 6: 18765.

41. Jenkins V, Thwaites R, Cercignani M, et al. (2016): A feasibility study exploring the role of pre-operative assessment when examining the mechanism of "chemo-brain" in breast cancer patients. SpringerPlus 5: 390.

42. Joshi BH, Leland P, Lababidi S, et al. (2014): Interleukin-4 receptor alpha overexpression in human bladder cancer correlates with the pathological grade and stage of the disease. Cancer Med 3: 1615-1628.

43. Juang Y-L, Jeng Y-M, Chen C-L, Lien H-C (2016): PRRX2 as a novel TGF- $\beta$-induced factor enhances invasion and migration in mammary epithelial cell and correlates with poor prognosis in breast cancer. Mol Carcinog 55: 2247-2259.

44. Katz LH, Likhter M, Jogunoori W, et al. (2016): TGF- $\beta$ signaling in liver and gastrointestinal cancers. Cancer Lett 379: 166-172.

45. Wang H, Wang L, Chi P, et al. (2016): High level of interleukin-10 in serum predicts poor prognosis in multiple myeloma. Br J Cancer 114: 463-468.

46. Hagstrom AD, Marshall PWM, Lonsdale C, et al. (2016): The effect of resistance training on markers of immune function and inflammation in previously sedentary women recovering from breast cancer: a randomized controlled trial. Breast Cancer Res Treat 155: 471-482.

47. Reed RG, Weihs KL, Sbarra DA, et al. Emotional acceptance, inflammation, and sickness symptoms across the first two years following breast cancer diagnosis. Brain Behav Immun 56: 165-174.

48. Cai C, Zhang J, Li M, et al. (2015): Interleukin 10-expressing $\mathrm{B}$ cells inhibit tumor-infiltrating T cell function and correlate with T cell Tim-3 expression in renal cell carcinoma. Tumour Biol J Int Soc Oncodevelopmental Biol Med 37: 8209-8218.

49. Arantes DAC, Costa NL, Mendonça EF, et al. (2016): Overexpression of immunosuppressive cytokines is associated with poorer clinical stage of oral squamous cell carcinoma. Arch Oral Biol 61: 28-35.

50. Nowak M, Glowacka E, Kielbik M, et al. (2016): Secretion of cytokines and heat shock protein (HspA1A) by ovarian cancer cells depending on the tumor type and stage of disease. Cytokine 89: 136-142.

51. Nelms K, Keegan AD, Zamorano J, et al. (1999): The IL-4 receptor: signaling mechanisms and biologic functions. Annu Rev Immunol 17: 701-738.

52. Bankaitis KV, Fingleton B (2015): Targeting IL4/IL4R for the treatment of epithelial cancer metastasis. Clin Exp Metastasis 32: 847-856.

53. Rabin EM, Mond JJ, Ohara J, Paul WE (1986): B cell stimulatory factor 1 (BSF-1) prepares resting B cells to enter $\mathrm{S}$ phase in response to anti-IgM and lipopolysaccharide. J Exp Med 164: 517-531.

54. Zubiaga AM, Munoz E, Huber BT (1992): IL-4 and IL-2 selectively rescue Th cell subsets from glucocorticoid-induced apoptosis. J Immunol 149: 107-112.

55. Schultze JL, Michalak S, Seamon MJ, et al. (1997): CD40activated human B cells: an alternative source of highly efficient antigen presenting cells to generate autologous antigen-specific T cells for adoptive immunotherapy. J Clin Invest 100: $2757-2765$. 
56. Suzuki A, Leland P, Joshi BH, Puri RK (2015): Targeting of IL-4 and IL-13 receptors for cancer therapy. Cytokine 75: 7988.

57. Hasbold J, Lyons AB, Kehry MR, Hodgkin PD (1998): Cell division number regulates $\operatorname{IgG} 1$ and $\mathrm{IgE}$ switching of B cells following stimulation by CD40 ligand and IL-4. Eur J Immunol 28: 1040-1051.

58. May RD, Fung M (2015): Strategies targeting the IL-4/IL-13 axes in disease. Cytokine 75: 89-116.

59. Mosmann TR, Coffman RL (1989): TH1 and TH2 Cells: Different Patterns of Lymphokine Secretion Lead to Different Functional Properties. Annu Rev Immunol 7: 145-173.

60. Hallett MA, Venmar KT, Fingleton B (2012): Cytokine stimulation of epithelial cancer cells: the similar and divergent functions of IL4 and IL13. Cancer Res 72: 6338-6343.

61. Prokopchuk O, Liu Y, Henne-Bruns D, Kornmann M (2005): Interleukin-4 enhances proliferation of human pancreatic cancer cells: evidence for autocrine and paracrine actions. $\mathrm{Br}$ J Cancer 92: 921-928.

62. Rahaman SO, Vogelbaum MA, Haque SJ (2005): Aberrant Stat3 Signaling by Interleukin-4 in Malignant Glioma Cells: Involvement of IL-13R $\alpha 2$. Cancer Res 65: 2956-2963.

63. Murata T, Obiri NI, Puri RK (1997): Human ovarian-carcinoma cell lines express IL-4 and IL-13 receptors: comparison between IL-4- and IL-13-induced signal transduction. Int J Cancer 70: $230-240$.

64. Kawakami M, Kawakami K, Stepensky VA, et al. (2002): Interleukin 4 Receptor on Human Lung Cancer. Am Assoc Cancer Res 8: 3503-3511.

65. Venmar KT, Kimmel DW, Cliffel DE, Fingleton B (2015): IL4 receptor $\alpha$ mediates enhanced glucose and glutamine metabolism to support breast cancer growth. Biochim Biophys Acta 1853: 1219-1228.

66. Koller FL, Hwang DG, Dozier EA, Fingleton B (2010): Epithelial interleukin-4 receptor expression promotes colon tumor growth. Carcinogenesis 31: 1010-1017.

67. Todaro M, Lombardo Y, Francipane MG, et al. (2008): Apoptosis resistance in epithelial tumors is mediated by tumor-cell-derived interleukin-4. Cell Death Differ 15: 762-772.

68. Kavanagh ME, Conroy MJ, Clarke NE, et al. (2016): Impact of the inflammatory microenvironment on T-cell phenotype in the progression from reflux oesophagitis to Barrett oesophagus and oesophageal adenocarcinoma. Cancer Lett 370: 117-124.

69. Nishio M, Urakawa N, Shigeoka M, et al. (2016): Software-assisted morphometric and phenotype analyses of human peripheral blood monocyte-derived macrophages induced by a microenvironment model of human esophageal squamous cell carcinoma: Image analysis of human PBMo-derived macrophages. Pathol Int 66: 83-93.

70. Sahoo A, Wali S, Nurieva R (2016): T helper 2 and T follicular helper cells: Regulation and function of interleukin-4. Cytokine Growth Factor Rev 30: 29-37.

71. Yanagida M, Fukamachi H, Ohgami K, et al. (1995): Effects of T-helper 2-type cytokines, interleukin-3 (IL-3), IL-4, IL-5, and IL- 6 on the survival of cultured human mast cells. Blood 86: $3705-3714$

72. Lutz MB, Schnare M, Menges M, et al. (2002): Differential Functions of IL-4 Receptor Types I and II for Dendritic Cell Maturation and IL-12 Production and Their Dependency on GM-CSF. J Immunol 169: 3574-3580.

73. Doseff AI, Baker JH, Bourgeois TA, Wewers MD (2003): Interleukin-4-Induced Apoptosis Entails Caspase Activation and Suppression of Extracellular Signal-Regulated Kinase Phosphorylation. Am J Respir Cell Mol Biol 29: 367-374.

74. Zhang J, Bárdos T, Shao Q, et al. (2003): IL-4 Potentiates Activated T Cell Apoptosis Via an IL-2-Dependent Mechanism. J Immunol 170: 3495-3503.

75. Li Z, Chen L, Qin Z (2009): Paradoxical Roles of IL-4 in Tumor Immunity. Cell Mol Immunol 6: 415-422.

76. Vento-Tormo R, Company C, Rodríguez-Ubreva J, et al. (2016): IL-4 orchestrates STAT6-mediated DNA demethylation leading to dendritic cell differentiation. Genome Biol 17: 4 .

77. Colangelo T, Polcaro G, Ziccardi P, et al. (2016): The miR-27a-calreticulin axis affects drug-induced immunogenic cell death in human colorectal cancer cells. Cell Death Dis 7: e2108.

78. Gableh F, Saeidi M, Hemati S, et al. (2016): Combination of the toll like receptor agonist and $\alpha$-Galactosylceramide as an efficient adjuvant for cancer vaccine. J Biomed Sci 23: 16.

79. Dong T, Yi T, Yang M, et al. (2016): Co-operation of $\alpha$-galactosylceramide-loaded tumour cells and TLR9 agonists induce potent anti-tumour responses in a murine colon cancer model. Biochem J 473: 7-19.

80. Fellerhoff-Losch B, Korol SV, Ganor Y, et al. (2016): Normal human CD4(+) helper T cells express Kv1.1 voltage-gated $\mathrm{K}(+)$ channels, and selective Kv1.1 block in T cells induces by itself robust $\mathrm{TNF} \alpha$ production and secretion and activation of the NFKB non-canonical pathway. J Neural Transm (Vienna) 123: 137-157.

81. Khademi B, Tajvarpour M, Mojtahedi Z, et al. (2016): T-helper Type 1 and 2 Cytokine Levels in Patients with Benign and Malignant Salivary Gland Tumors. Iran J Immunol 13: 9-15.

82. Lam JO, Bream JH, Sugar EA, et al. (2016): Association of serum cytokines with oral HPV clearance. Cytokine 83: 85-91.

83. Lee C-R, Lee SH, Rigas NK, et al. (2016): Elevated expression of JMJD6 is associated with oral carcinogenesis and maintains cancer stemness properties. Carcinogenesis 37: 119-128.

84. Comstock SS, Xu D, Hortos K, et al. (2016): Association of serum cytokines with colorectal polyp number and type in adult males: Eur J Cancer Prev 25: 173-181.

85. Grygorowicz MA, Borycka IS, Nowak E, et al. (2016): Lenalidomide potentiates CD4(+)CD25(+)Treg-related suppression of lymphoma B-cell proliferation. Clin Exp Med 17: 193-207.

86. Singh D, Upadhyay G, Srivastava RK, Shankar S (2015): Recent advances in pancreatic cancer: biology, treatment, and prevention. Biochim Biophys Acta 1856: 13-27.

87. Cantelli G, Orgaz JL, Rodriguez-Hernandez I, et al. (2015): TGF- $\beta$-Induced Transcription Sustains Amoeboid Melanoma Migration and Dissemination. Curr Biol 25: 2899-2914.

88. Barcellos-Hoff MH, Cucinotta FA (2014): New tricks for an old fox: Impact of TGF on the DNA damage response and genomic stability. Sci Signal 7: re5-re5.

89. Sheen YY, Kim M-J, Park S-A, et al. (2013): Targeting the Transforming Growth Factor- $\beta$ Signaling in Cancer Therapy. Biomol Ther 21: 323-331.

90. Sato M, Kadota M, Tang B, et al. (2014): An integrated genomic approach identifies persistent tumor suppressive effects of transforming growth factor- $\beta$ in human breast cancer. Breast Cancer Res 16: R57.

91.Principe DR, Doll JA, Bauer J, et al. (2014): TGF- $\beta$ : Duality of Function Between Tumor Prevention and Carcinogenesis. J Natl Cancer Inst 106: djt369.

92. Travis MA, Sheppard D (2014): TGF- $\beta$ activation and function in immunity. Annu Rev Immunol 32: 51-82. 
93. Li MO, Wan YY, Sanjabi S, et al. (2006): Transforming growth factor- $\beta$ regulation of immune responses. Annu Rev Immunol 24: 99-146.

94. Zi Z, Chapnick DA, Liu X (2012): Dynamics of TGF- $\beta /$ Smad signaling. FEBS Lett 586: 1921-1928.

95. Zhang J, Tian X-J, Xing J (2016): Signal Transduction Pathways of EMT Induced by TGF- $\beta$, SHH, and WNT and Their Crosstalks. J Clin Med 5: 41.

96. David CJ, Huang Y-H, Chen M, et al. (2016): TGF- $\beta$ Tumor Suppression through a Lethal EMT. Cell 164: 1015-1030.

97. Ma B, Cheng H, Gao R, et al. (2016): Zyxin-Siah2-Lats2 axis mediates cooperation between Hippo and TGF- $\beta$ signalling pathways. Nat Commun 7: 11123.

98. Rong L, Li R, Li S, Luo R (2016): Immunosuppression of breast cancer cells mediated by transforming growth factor $\beta$ in exosomes from cancer cells. Oncol Lett 11: 500-504.

99. Farhana L, Antaki F, Anees MR, et al. (2016): Role of cancer stem cells in racial disparity in colorectal cancer. Cancer Med 5: 1268-1278.

100. Elmansuri AZ, Tanino MA, Mahabir R, et al. (2016): Novel signaling collaboration between TGF- $\beta$ and adaptor protein Crk facilitates EMT in human lung cancer. Oncotarget 7: 27094-27107.

101. Pavlides SC, Lecanda J, Daubriac J, et al. (2016): TGF- $\beta$ activates APC through Cdh1 binding for Cks1 and Skp2 proteasomal destruction stabilizing p27kip1 for normal endometrial growth. Cell Cycle Georget Tex 15: 931-947.

102. Chen C, Xue Y, Zhang D, et al. (2016): Short hairpin RNA silencing of TGF- $\beta$ RII and FZD-7 synergistically suppresses proliferation and metastasis of hepatocellular carcinoma cells. Oncol Lett 11: 2039-2046.

103. Ihle NT, Williams R, Chow S, et al. (2004): Molecular pharmacology and antitumor activity of PX-866, a novel inhibitor of phosphoinositide-3-kinase signaling. Mol Cancer Ther 3: 763-772.

104. Peek GW, Tollefsbol TO (2016): Down-regulation of hTERT and Cyclin D1 transcription via PI3K/Akt and TGF- $\beta$ pathways in MCF-7 Cancer cells with PX-866 and Raloxifene. Exp Cell Res 344: 95-102.

105. Zhang C, Lu Y, Li Q, et al. (2016): Salinomycin suppresses TGF- $\beta 1$-induced epithelial-to-mesenchymal transition in MCF-7 human breast cancer cells. Chem Biol Interact 248: 74-81.

106. Cheng J, Yang K, Zhang Q, et al. (2016): The role of mesenchymal stem cells in promoting the transformation of androgen-dependent human prostate cancer cells into androgen-independent manner. Sci Rep 6: 16993.

107. Cao W-H, Liu X-P, Meng S-L, et al. (2016): USP4 promotes invasion of breast cancer cells via Relaxin/TGF- $\beta 1 / \mathrm{Smad} 2 /$ MMP-9 signal. Eur Rev Med Pharmacol Sci 20: 1115-1122.

108. Zhang L, Cheng X, Gao Y, et al. (2016): Curcumin inhibits metastasis in human papillary thyroid carcinoma BCPAP cells via down-regulation of the TGF- $\beta / \mathrm{Smad} 2 / 3$ signaling pathway. Exp Cell Res 341: 157-165.

109. Da C, Liu Y, Zhan Y, et al. (2016): Nobiletin inhibits epithelial-mesenchymal transition of human non-small cell lung cancer cells by antagonizing the TGF- $\beta 1 / \mathrm{Smad} 3$ signaling pathway. Oncol Rep 35: 2767-2774.

110. Nie Z, Wang C, Zhou Z, et al. (2016) Transforming growth factor-beta increases breast cancer stem cell population partially through upregulating PMEPA1 expression. Acta Biochim Biophys Sin 48:194-201.
111. Iwasaki M, Zhao H, Jaffer T, et al. (2016): Volatile anaesthetics enhance the metastasis related cellular signalling including CXCR2 of ovarian cancer cells. Oncotarget 7: 26042-2605.

112. Gupta S, Hau AM, Al-Ahmadie HA, et al. (2016): Transforming Growth Factor- $\beta$ Is an Upstream Regulator of Mammalian Target of Rapamycin Complex 2-Dependent Bladder Cancer Cell Migration and Invasion. Am J Pathol 186: $1351-1360$.

113. Tian Y, Yu Y, Hou L, et al. (2016): Serum deprivation response inhibits breast cancer progression by blocking transforming growth factor- $\beta$ signaling. Cancer Sci 107: 274-280.

114. Hino M, Kamo M, Saito D, et al. (2016): Transforming growth factor- $\beta 1$ induces invasion ability of HSC-4 human oral squamous cell carcinoma cells through the Slug/Wnt-5b/ MMP-10 signalling axis. J Biochem (Tokyo) 159: 631-640.

115. Majumder S, Bhowal A, Basu S, et al. (2016): Deregulated E2F5/p38/SMAD3 Circuitry Reinforces the Pro-Tumorigenic Switch of TGF $\beta$ Signaling in Prostate Cancer. J Cell Physiol 231: 2482-2492.

116. Sun W, Gui L, Zuo X, et al. (2016): Human epithelial-type ovarian tumour marker beta-2-microglobulin is regulated by the TGF- $\beta$ signaling pathway. J Transl Med 14: 75.

117. Zhu Z, Wang Y, Zhang C, et al. (2016): TRIM25 blockade by RNA interference inhibited migration and invasion of gastric cancer cells through TGF- $\beta$ signaling. Sci Rep 6: 19070.

118. Carl C, Flindt A, Hartmann J, et al. (2016): Ionizing radiation induces a motile phenotype in human carcinoma cells in vitro through hyperactivation of the TGF-beta signaling pathway. Cell Mol Life Sci 73: 427-443.

119. Cheng Y, Guo Y, Zhang Y, et al. (2016): MicroRNA-106b is involved in transforming growth factor $\beta 1$-induced cell migration by targeting disabled homolog 2 in cervical carcinoma. J Exp Clin Cancer Res 35: 11.

120. Kuninty PR, Bojmar L, Tjomsland V, et al. (2016): MicroRNA-199a and -214 as potential therapeutic targets in pancreatic stellate cells in pancreatic tumor. Oncotarget 7: 16396-16408.

121. Zhang F, Luo Y, Shao Z, et al. (2016): MicroRNA-187, a downstream effector of TGF $\beta$ pathway, suppresses Smad-mediated epithelial - mesenchymal transition in colorectal cancer. Cancer Lett 373: 203-213. 